\title{
Construction of a Cost-Effective Domestic Wastewater Disinfection Filter from Biosynthesized Compared to Commercial Nanosilver
}

Heba S. Taher ( $\square$ hebasaadtaher2003@gmail.com )

Suez Canal University Faculty of Science https://orcid.org/0000-0003-1727-289X

Rania Sayed

Nanotechnology and Nanometrology Laboratory-National Institute of Standards- Egypt

Asmaa Loutfi

Suez Canal University

Hesham Mohammed Abdulla

Suez Canal University

\section{Research Article}

Keywords: Silver nanoparticles, Nanometrological measurements, Streptomyces, Characteristics, Wastewater disinfection, Coliform.

Posted Date: July 7th, 2021

DOI: https://doi.org/10.21203/rs.3.rs-572443/v1

License: (9) This work is licensed under a Creative Commons Attribution 4.0 International License. Read Full License 


\section{Abstract}

Biosynthesis of nanoparticles is considered one of the most significant aspects of nanotechnology, it is an eco-friendly process. In this paper, Streptomyces sp. U13 (KP109813) was used to biosynthesize silver nanoparticles (Ag NPs) to construct a cost-effective wastewater disinfection filter. A comparison between the biosynthesized nanosilver and a commercially available ink nanosilver was done on both their characteristics and wastewater disinfection efficiency. The nanometrological characteristics of the biosynthesized and commercially available nanosilver such as structure, shape, size, and optical properties were investigated using the X-ray diffraction (XRD), Fourier transform infrared spectroscopy (FTIR), high resolution transmission electron microscope (HR-TEM), and UV-Visible spectroscopy, respectively. Ag NPs were loaded on two substrates, foam and limestone gravel. Ag NPs attached to limestone gravel better than foam and eliminated all coliforms. Wastewater disinfection under different conditions was tested. The results concluded that the type of substrate controls the amount of Ag NPs that loaded on it and thus control the disinfection process. No significant difference between using biosynthesized nanosilver and commercially available ink nanosilver in wastewater disinfection. Using limestone gravel filter loaded with $200 \mathrm{mg} / \mathrm{Ag}$ NPs with contact time $150 \mathrm{~min}$ are required to reduce the number of coliforms to nil.

\section{Introduction}

Nanotechnology is an emerging and fast-growing technology. Currently, there are a huge number of nanotechnology-based products on market. Nanomaterial is known as a natural, incidental, or manufactured material having particles, in an unbound state or as an aggregate or as an agglomerate and where one or more of the external dimensions are in the size range 1-100 nm (Bondarenko et al. 2013). The use of nanomaterials is expanded in a wide range of applications such as energy, health, and environment.

Variety of synthesis processes have been reported for nanoparticles preparation and characterization. Physical methods are costly and chemical methods are toxic (Parisa et al. 2015). Biological methods via plants and microorganisms (Jannathul et al. 2015; Benakashani et al. 2016; Erico et al. 2016; BakhtiariSardari et al. 2020) are promising green alternative. Among all manufactured nanomaterials, nano-sized silver is the most widely used in different applications. Silver nanoparticles (Ag NPs) possess unique physicochemical properties (Elechiguerra et al. 2005) that open a wide range of applications, one of which is water purification (Bielefeldt et al. 2009). It is mainly used to remove three major pollutants, pesticides, heavy metals, and microorganisms (Que et al. 2018). Ag NPs are known as excellent antimicrobial agents; they could be used as alternative disinfectants in water treatment systems (Bielefeldt et al. 2009; Sayed et al. 2018).

Actinomycetes are Gram-positive filamentous bacteria with high GC content. It is used in nanotechnology because of its unique capability to produce various bioactive component and high protein content to produce nanoparticles both intracellularly and extracellularly (Gahlawat and Choudhury 2019). Several 
studies proved that Streptomyces could synthesise Ag NPs by direct contact with mycelial mass (Tsibakhashvili et al. 2011) cell free metabolites (Vidhyashree et al. 2015; Al-Dhabi et al. 2019; BakhtiariSardari et al. 2020), or partially purified metabolite (Abou-Dobara et al. 2017).

The multiple pressures of climate change, population growth, industrialization and urbanization have led to declining availability of freshwater resources (Sun et al. 2016). According to the World Health Organization (WHO), more than 1.5 million children die each year due to bad sanitation (WHO 2015). Wastewater discharges in water resources are the major source of pathogens. Safe management of wastewater can yield multiple benefits, in this context, there is a real requirement for more efficient and powerful technologies for treatment of wastewater (Ferroudj et al. 2013). Chlorination is extensively used for disinfecting sewage effluents, but by-products such as toxic organic halogen could be produced (Chu et al. 2016). Ozone requires the use of complicated equipment, while bacterial re-growth is possible after UV irradiation (Wang et al. 2015).

The ideal disinfectant should possess broad antimicrobial spectrum within short time, no generation of harmful by-products, low energy cost, easy operation and easy to store, must not be corrosive and capable of safe disposal. Silver in the form of nanoparticles that release silver ions more effectively has a better bactericidal activity due to its high surface area to volume ratio (Duran et al. 2010). Researchers deposited Ag NPs on different solid materials for wastewater treatment like sand (Mahmood et al. 1993), zeolite (Matsumura et al. 2003), fibreglass (Nangmenyi et al. 2009), silica micro beads (Quang et al. 2011), cotton, wool, and nylon fabrics (Pasricha et al. 2012), resin beads (Mthombenia et al. 2012), activated carbon (Altintig et al. 2016), foams (Moustafa 2017) and magnetic biochar/poly (dopamine) composite (Li et al. 2019). These reports showed that the type of substrate controls the amount of $\mathrm{Ag}$ NPs that loaded on it and thus control the disinfection process.

The present study deals with construction of a cost-effective wastewater disinfection filter employed biosynthesized silver nanoparticles using actinomycete strain and investigating their characteristics compared to commercially available silver nanoparticles.

\section{Materials And Methods}

\subsection{Silver tolerance and strains selection:}

Native actinomycete strains were isolated from sandstone rock collected from Um Bogma village, Sinai, Egypt (Abdulla et al. 2018). They were screened for $\mathrm{Ag}^{+}$tolerance at different concentrations. To assess the tolerance, $\mathrm{Ag}^{+}$(as $\mathrm{AgNO}_{3}$ ) was added to starch casein agar medium at concentrations 100, 300 and $500 \mathrm{ppm}$, plates were then spot inoculated by spore suspension and incubated at $28{ }^{\circ} \mathrm{C}$ for 7 days. Growth diameters were compared to the growth on control plates (medium without $\mathrm{Ag}^{+}$). The following formula was used to calculate the tolerance: 


\subsection{Biosynthesis of Ag NPs:}

Six tolerant actinomycete strains were examined for Ag NPs synthesis. Spores of the selected strains were inoculated into starch casein broth and incubated at $28{ }^{\circ} \mathrm{C}$ under continuous agitation at $100 \mathrm{rpm}$ for 3 days. The biomass was harvested by centrifugation and then rinsed twice with distilled water. The washed pellets were resuspended in sterile tap water. To determine the dry weight, an aliquot of the suspension was centrifuged and dried overnight at $60{ }^{\circ} \mathrm{C}$ to a constant weight. $25 \mathrm{mg}$ dry weight equivalent of each strain were washed twice with deionized water and resuspended in $100 \mathrm{ml}$ of $25 \mathrm{mg}$ $\mathrm{Ag}^{+} / \mathrm{I}, \mathrm{pH}$ was adjusted to 7. Screening experiment for biosynthesis of Ag NPs was carried out in duplicate at $28{ }^{\circ} \mathrm{C}$ overnight, development of brown colour was considered positive result, and this was confirmed by UV-Vis scan.

Streptomyces sp. U13 (KP109813) was selected as the most active isolate. It was examined to synthesise Ag NPs at different $\mathrm{Ag}^{+}$concentrations $(25,50,75$ and $100 \mathrm{mg} / \mathrm{l})$ and at different biomass weights (20, $40,60,80$ and $100 \mathrm{mg}$ dry weight equivalent) at $\mathrm{pH} 7$ while incubated overnight at $28^{\circ} \mathrm{C}$. The best conditions were selected to biosynthesise Ag NPs to be characterized and used in the wastewater disinfection experiments compared to commercially available ink Ag NPs (Sayed et al. 2018).

\subsection{Ag NPs characterization:}

Different techniques were used to study the nanometrological characteristics of the biosynthesized Ag NPs and commercially available ink Ag NPs. UV-Vis spectrophotometer (ShimaDZU, UV3101PC, Japan) was used to confirm the formation of Ag NPs in solution at room temperature. The absorbance spectra were recorded from 300 to $700 \mathrm{~nm}$ with a $1 \mathrm{~nm}$ interval. The X-ray diffraction analysis (XRD) was carried out by diffractometer (D8 Advance, BRUKER, Germany) with Cu-Ka ( $\lambda=1.542 \AA$ ) operated at $45 \mathrm{kV}$ and 40 $\mathrm{mA}$ at room temperature. The analysis was done in the wide angle range from $10^{\circ}$ to $80^{\circ}$ with step $0.02^{\circ}$. The chemical structure of Ag NPs was investigated by using a Fourier transform infrared spectrometer (FT/IR-4100 type A, JASCO, Japan). The measurements were performed at wavenumber range from 4000 to $450 \mathrm{~cm}^{-1}$ at a resolution of $0.96 \mathrm{~cm}^{-1}$. High resolution transmission electron microscopy (HR-TEM, Jeol JEM 2100, Japan) with an acceleration voltage of $200 \mathrm{kV}$ was used to determine the size and shape of Ag NPs. The TEM sample was prepared by dropping the suspension of Ag NPs on a copper grid and allowed to dry at room temperature.

\subsection{Wastewater disinfection experiments:}

Domestic wastewater samples were collected from pre-chlorination stage from Sarabium wastewater treatment plant in Ismailia, Egypt and were used in the same day of sampling. Disinfection was evaluated by detection of total coliform; a subsample was taken before disinfection for the initial count. Total 
coliform was cultured on Endobase medium (Lab M-England) after serial dilutions using pour plate technique followed by incubation at $37^{\circ} \mathrm{C}$ for $24 \mathrm{hrs}$.

\subsubsection{Coating of silver nanoparticles on substrate:}

Two substrates, foam, and limestone gravel were selected to carry the biosynthesized Ag NPs due to their high surface area. $240 \mathrm{~g}$ of each substrate with diameter $(6-8 \mathrm{~mm})$ was washed twice by distilled water with shaking for $30 \mathrm{~min}$. Washed substrates were soaked in suspension of Ag NPs ( $250 \mathrm{ml})$ with concentration $400 \mathrm{mg} / \mathrm{l}$ on shaker for $24 \mathrm{hrs}$ in dark. Each coated substrate $(240 \mathrm{~g})$ was used to fill a glass column (4 cm diameter, $23 \mathrm{~cm}$ height).

\subsubsection{Column experiment:}

$150 \mathrm{ml}$ of domestic wastewater were poured in each column in compared to control, the columns were conducted in duplicates. Samples were taken after $6 \mathrm{hrs}$ to evaluate the disinfection capacity and silver discharge was measured by atomic absorption spectroscopy (PerkinElmer).

\subsubsection{Column experiment with different conditions:}

Limestone gravel was chosen as a substrate to test different disinfection conditions. These conditions were disinfection mode, nanoparticles concentration and nanosilver type (the biosynthesized compared to commercially ink Ag NPs). Two modes were tested for the disinfection process, continuous flow mode and static mode. In the continuous flow mode, the wastewater was run from a reservoir to the column with flow rate $2 \mathrm{ml} / \mathrm{min}$. In the static mode, the wastewater was retained in column and a sample was taken periodically each 30 mins. Another concentration of the biosynthesized Ag NPs (200 mg/l) was used to coat gravel and disinfect wastewater under static mode.

To evaluate the disinfection process using the biosynthesized Ag NPs compared to commercially available source, ink Ag NPs was chosen (Fig. 1). The biosynthesized Ag NPs and ink Ag NPs at concentration $200 \mathrm{mg} / \mathrm{l}$ were used to coat and assembled the columns as mentioned above and the disinfection process was evaluated using static mode.

\section{Results And Discussion}

\subsection{Silver tolerance and strains selection:}

Silver ion tolerance experiment was conducted to correlate the tolerance to synthesis process. The six screened strains (U9, U12, U13, U17, U19 and U30) tolerate $\mathrm{Ag}^{+}$up to $300 \mathrm{mg} / \mathrm{l}$, only four of them grew at $500 \mathrm{mg} / \mathrm{l}$ (Fig. 2). U13 was the most tolerant by showing a tolerance percentage of $56 \%$ at $500 \mathrm{mg} / \mathrm{I} \mathrm{Ag}^{+}$. Bacteria have different strategies to combat heavy metals toxicity. Biosorption of silver ions onto Grampositive bacterial biomass in crystalline forms has been suggested as a possible mechanism of resistance (Li et al. 2011). Gelagutashvili (2013), found the efficiency of biosorption of $\mathrm{Cr}(\mathrm{III}), \mathrm{Cr}(\mathrm{VI})$, $\mathrm{Cd}(\mathrm{II}), \mathrm{Au}(\mathrm{III})$ and $\mathrm{Ag}(\mathrm{I})$ ions depends on bacterial strain and uptake conditions. 


\subsection{Biosynthesis of Ag NPs:}

The formation of Ag NPs was observed visually by change of solution colour from colourless to brown. Streptomyces sp. U13 showed change in solution colour (Fig. 3), while the rest strains only the biomass colour was changed to greyish brown with slight change in colour of the solution. Extracellular formation of Ag NPs was confirmed by UV-Vis scan from 300 to $700 \mathrm{~nm}$. The UV-visible spectra (Fig. 4) showed increased absorbance and a peak was recorded at $434 \mathrm{~nm}$ only in case of Streptomyces sp. U13. Several studies proved that numerous strains of Streptomyces synthesise Ag NPs (Vidhyashree et al. 2015; AbouDobara et al. 2017; Al-Dhabi et al. 2019; Bakhtiari-Sardari et al. 2020).

Streptomyces strains can synthesise Ag NPs intracellularly and extracellularly. Although the biomass colour of the rest tested strains was changed indicating intracellular biosynthesis, only the extracellular Ag NPs were characterized. Extraction of the intracellular Ag NPs needs application of suitable detergents or ultrasonic treatment. Economically, extracellular synthesis of Ag NPs is preferred for large-scale production because it is cheap, simple and can be easily purified. Streptomyces mechanisms for reducing $\mathrm{AgNO}_{3}$ into Ag NPs are not fully recognized. Ag NPs could be synthesized by direct contact with mycelial mass (Tsibakhashvili et al. 2011), cell free metabolites (Vidhyashree et al. 2015; Al-Dhabi et al. 2019; Bakhtiari-Sardari et al. 2020), or partially purified metabolite (Abou-Dobara et al. 2017).

UV-vis scan results reflect differences in Ag NPs characterization as well as in quantity. Increasing $\mathrm{Ag}^{+}$ concentrations increased the quantity of the produced Ag NPs, as shown in Fig. 5a and 5c. The colour of the solutions became darker, and the absorbance increased in spectrophotometric scanning. Using 100 $\mathrm{mg} \mathrm{Ag}^{+} /$( (equivalent to $1 \mathrm{mM} \mathrm{AgNO}_{3}$ ), the highest Ag NPs concentration was obtained as shown in scan curve height (Fig. 5a). Dada et al. (2018), reported that most appropriate and suitable concentration of $\mathrm{AgNO}_{3}$ is $1 \mathrm{mM}$ as where better surface plasmon resonance was obtained. Wagi and Ahmed (2020), found that increasing in $\mathrm{Ag} \mathrm{NPs}$ due to $\mathrm{AgNO}_{3}$ increase is not the case for every strain and varies from species to species.

Increasing biomass weights also affecting the synthesis process by increasing the produced Ag NPs quantity (Fig. 5b), but when the biomass elevated to $100 \mathrm{mg}$ (dry weight equivalent), the produced $\mathrm{Ag}$ NPs became greyish and precipitated rapidly. The results showed that the best conditions for synthesis of Ag NPs were $100 \mathrm{mg} \mathrm{Ag}^{+} / /$and $80 \mathrm{mg}$ dry weight equivalent. These conditions were selected to synthesise Ag NPs to be characterized and used in the wastewater disinfection experiments.

\subsection{Ag NPs characterization:}

\subsubsection{UV-Vis spectroscopy}

Absorption band in the visible region considers the main characteristic of silver nanoparticles. Optical absorption spectra of Ag NPs are dominated by surface plasmon band which shows red end or blue end shift depends on size, shape, and aggregation of the particles (Lufsyi et al. 2015). Figure 6a showed that successfully biosynthesized silver nanoparticles, with light brown colour, had the surface plasmon 
absorption band with a maximum of $434 \mathrm{~nm}$ in the visible region. In Fig. 6b, abroad signal in the visible range with a maximum at about $414 \mathrm{~nm}$ was observed for commercially available synthesised silver nanoparticles (ink nanosilver) with dark brown colour due to the combined vibration of Ag NPs in resonance with the light wave (Dubey et al. 2010). The wideness of the absorption spectrum curves is good evidence of the nanoparticle size and the two observed absorption bands of Ag NPs indicate the presence of spherical or roughly spherical shape of particles (Guzmán et al. 2008).

\subsubsection{X-ray diffraction studies (XRD):}

The XRD pattern of biologically and commercially available synthesised silver nanoparticles was recorded in the range between 20 and $80^{\circ}(2 \theta)$, step of $0.04^{\circ}$ and 2 sec per step. The samples for XRD analysis were prepared by using a pipette to put drops of Ag NPs solution on a glass slide to achieve uniformly thin films. The XRD pattern of the biosynthesized Ag NPs sample was illustrated in Fig. 6c. The XRD pattern showed the Bragg's diffraction peaks of Ag NPs at $38.16^{\circ}, 45.04^{\circ}$ and $64.75^{\circ}$, respectively corresponding to (111), (200) and (220) planes of the face centred cubic lattice. The other peak at $32.78^{\circ}$ may be appeared due to crystallization of bio-organic phase (Sathiya et al. 2014; Selvi et al. 2016). These results are in a good agreement with reported results on previous literature (Probin et

al. 2015; Vasudeva et al. 2018). Figure 6d shows that the commercially available synthesized Ag NPs (ink nanosilver) are found to be amorphous. These results are in line with previous reports (Harajyoti et al. 2011; Sayed et al. 2018).

\subsubsection{Fourier transform-infrared spectroscopy analysis (FTIR):}

FTIR analysis was performed for biosynthesized and commercially available Ag NPs. The biosynthesized Ag NPs shows absorption peaks at 3449.06, 2092.39, 1637.27, 1460.81, 1259.29 and 1161.9 as shown in Fig. 6e. The functional groups corresponding to these absorption peaks are $\mathrm{O}-\mathrm{H}$ stretching, $\mathrm{C}=\mathrm{O}$ stretching, $\mathrm{C}=\mathrm{O}$ stretching of amide groups of proteins, amino and amino-methyl stretching groups of protein, $\mathrm{C}-\mathrm{O}-\mathrm{C}$ stretching and $\mathrm{C}-\mathrm{O}$ stretch (Probin et al. 2015; Vasudeva et al. 2018). The sharp absorption beak at $1637.27 \mathrm{~cm}^{-1}$ indicates that proteins are interacting with biosynthesized Ag NPs without affecting on their secondary structure during reaction with $\mathrm{Ag}^{+}$ions or after binding with $\mathrm{Ag}$ NPs (Fayez et al. 2010). The IR spectroscopic analysis confirms that presence of proteins acting as capping agent to prevent agglomeration of nanoparticles and provide stability to the medium (Sathyavathi et al. 2010).

FTIR spectrum of the commercially available Ag NPs (Ink nanosilver) was presented in Fig. $6 \mathrm{f}$. It shows that seven peaks located at 3470.28, 2096.24, 1639.2, 1436.71, 1163.83, 1114.65 and $1039.44 \mathrm{~cm}^{-1}$ are assigned for $\mathrm{O}-\mathrm{H}, \mathrm{C} \equiv \mathrm{C}, \mathrm{C}=\mathrm{C}, \mathrm{N}-\mathrm{H}, \mathrm{C}-\mathrm{O}, \mathrm{C}-\mathrm{O}$ and $\mathrm{C}-\mathrm{N}$ stretch vibration mode, respectively. The same results were reported on previous literature (Preetha et al. 2013; Kumari et al. 2016).

\subsubsection{High resolution transmission electron microscope (HR-TEM):}


ISO 21363:2020 (Nanotechnologies - Measurements of particle size and shape distributions by transmission electron microscope) has published recently by international organization for standardization (ISO) to study the morphology of nanoparticles. The size and shape of the two samples of silver nanoparticles were obtained by using the nanometrological technique HR-TEM. The samples were prepared by dropping Ag NPs solution onto a micro copper grid. TEM images Fig. $6 \mathrm{~g}$ and $6 \mathrm{~h}$ revealed that the biosynthesized Ag NPs and commercial Ag NPs (ink nanosilver) well dispersed and had spherical shape. The size of biosynthesized Ag NPs ranging from 5 to $37 \mathrm{~nm}$ with mean diameter $22.75 \pm$ $10.88 \mathrm{~nm}$ and the size of ink Ag NPs ranging from 2 to $26 \mathrm{~nm}$ with mean diameter $16.523 \pm 7.792 \mathrm{~nm}$.

\subsection{Wastewater disinfection experiments:}

Reduction of total coliform count after column experiment using the two tested substrates loaded with $\mathrm{Ag}$ NPs was shown in Fig. 7a. The results revealed that after 6 hrs the reduction percentage of total coliform count was $100 \%$ in limestone gravel column while $50 \%$ reduction was recorded in foam column. Silver discharged from limestone gravel column was less than $0.01 \mathrm{mg} / \mathrm{l}$ which is below the standards to be discharged into the aquatic environment (Standards and specifications for liquid wastes, 2015). This result may be due to that Ag NPs are stable and remains in zero-valent state, but unreduced $\mathrm{Ag}^{+}$can loaded onto the substrate and released much easier again (Pasricha et al. 2012). It worth to note that the used substrates have different binding capabilities to Ag NPs. Previous work by Pasricha et al. (2012) reported that cotton fabrics bind to Ag NPs more than wool and nylon.

The type of substrate controls the amount of Ag NPs that loaded on it and thus control the disinfection process. Moustafa (2017) removes $98.5 \%$ of $41 \times 10^{5} \mathrm{CFU}$ total coliform/100 ml after $24 \mathrm{~h}$ by foams that have been pre-soaked in $1118.6 \mathrm{mg} / \mathrm{l}$ Ag NPs. In this experiment, foams removed $50 \%$ of $25 \times 10^{5} \mathrm{CFU} / \mathrm{ml}$ after 6 hrs only, may be due to the lower loaded Ag NPs and contacting time. Limestone gravel is a high porous substrate and used in wastewater treatment processes (Fahim et al. 2019; El-Shahawy et al. 2020). Due to the higher efficiency of limestone than foam in binding and disinfection, limestone was chosen to test different disinfection conditions. As shown in Fig. 7b, the reduction percentage of total coliform count was $100 \%$ after 6 hrs of using continuous flow mode or static mode. Continuous flow mode was performed at $2 \mathrm{ml} / \mathrm{min}$, Mthombenia et al. (2012), also found that $2 \mathrm{ml} / \mathrm{min}$ was the most efficient flow rate.

The efficiency of disinfection system depends on different parameters, one of them is the concentration of the disinfectant. The increased concentration of Ag NPs ensures the complete disinfection process (Mpenyana-Monyatsi et al. 2012; Moustafa, 2017), but on the other hand it will certainly rise the cost and increase the discharged silver. Hence using lower but efficient Ag NPs concentration to coat the substrate will reduce the cost. The results showed that after half an hour the two tested concentration (200 and 400 $\mathrm{mg} / \mathrm{l}$ ) eliminate about $50 \%$ of the initial total coliform count. With time passing columns loaded with 400 $\mathrm{mg} / \mathrm{l}$ concentration gradually reduce the count more than $200 \mathrm{mg} / \mathrm{l}$ but both concentrations were completely eliminating the total coliform after $150 \mathrm{~min}$ (Fig. 8). $200 \mathrm{mg} / \mathrm{l}$ of the biosynthesized Ag NPs was considered the efficient concentration. 
The efficiency of Ag NPs in certain field depends on their characteristics. The biosynthesis process produced heterogeneous Ag NPs suspension in both shape and size. The commercial Ag NPs were more homogenous in shape and size. The efficiency of both biosynthesized and commercial Ag NPs was determined. After $90 \mathrm{~min}$ there was no difference in reduction percentage, and both completely eliminate the total coliform after 150 min (Fig. 9).

\section{Conclusions}

In summary, a simple, non-toxic, and eco-friendly method was used to biosynthesis silver nanoparticles by Streptomyces sp. U13 (KP109813). The nanometrological characterization of biosynthesized Ag NPs and commercial Ag NPs (Ink nanosilver) were studied for using them in wastewater disinfection. Two types of substrate, foam, and limestone gravel were selected to carry silver nanoparticles due to their high surface area. The type of the substrate controls the amount of Ag NPs that loaded on it and thus control the disinfection process. Limestone gravel is a high porous substrate and possesses higher efficiency of Ag NPs binding than foam. The results revealed that there was no significance between using biologically synthesised and commercially available Ag NPs for reducing bacterial contamination in wastewater. The concentration $200 \mathrm{mg} / \mathrm{I}$ Ag NPs for coat limestone gravel with contact time $150 \mathrm{~min}$ are required to reduce the number of coliforms to nil.

\section{Declarations}

\section{Ethics approval and consent to participate:}

Not applicable

\section{Consent for publication:}

Not applicable

\section{Availability of data and materials:}

The datasets used and/or analysed during the current study are available from the corresponding author on reasonable request

\section{Competing interests:}

The authors declare that they have no competing interests

\section{Funding:}

This study was funded by Science \& Technology Development Fund (STDF) under Young Researcher Grant Agreement No 33466

\section{Authors' contributions:}


All authors read and approved the final manuscript

$\mathrm{HT}$ : Screening, synthesis, and disinfection experiments and writing the manuscript

RS: Characterizing Ag NPs, providing commercial ink Ag NPs and writing the manuscript

AL: Synthesis and disinfection experiments

HA: Reviewing the manuscript and research team leader

\section{Acknowledgments:}

This study was funded by Science \& Technology Development Fund (STDF) under Young Researcher Grant Agreement No 33466.

\section{References}

1. Abou-Dobara MI, El-Sayed A, Omar N, (2017) Streptomyces violaceoruber ES: A Producer of Bioprospective Metabolite for Rapid and Green Synthesis of Antibacterial Silver Nanoparticles. Egypt J of Bot 57 (3): 31-43. DOI: 10.21608/ejbo.2017.1017.1089

https://ejbo.journals.ekb.eg/article_4085.html

2. Al-Dhabi NA, Ghilan A, Esmail G, Arasu M, Veeramuthu, Duraipandiyan K and Ponmurugan K (2019)

Environmental friendly synthesis of silver nanomaterials from the promising Streptomyces parvus strain Al-Dhabi-91 recovered from the Saudi Arabian marine regions for antimicrobial and antioxidant properties. J Photochem Photobiol B Biol 197111529.

https://doi.org/10.1016/j.jphotobiol.2019.111529

3. Altintig E, Arabaci G, Altundag H (2016) Preparation and characterization of the antibacterial efficiency of silver loaded activated carbon from corncobs. Surf Coat Technol 304: 63-67. https://doi.org/10.1016/j.surfcoat.2016.06.077

4. Bakhtiari-Sardari A, Mashreghi M, Hossein E, Behnam-Rasouli F, Lashani E, Shahnavaz B (2020) Comparative evaluation of silver nanoparticles biosynthesis by two cold-tolerant Streptomyces strains and their biological activities. Biotechnol Lett 42:1985-1999. doi: 10.1007/s10529-02002921-1

5. Benakashania F, Allafchianb A, Jalali S (2016) Biosynthesis of silver nanoparticles using Capparisspinosa L. leaf extract and their antibacterial activity. Mod Sci 2: 251-258. https://doi.org/10.1016/j.kijoms.2016.08.004

6. Bielefeldt AR, Kowalski K, Summers R (2009) Bacterial treatment effectiveness of point-of-use ceramic water filters. Water Res 43: 3559-3565. doi: 10.1016/j.watres.2009.04.047

7. Bondarenko O, Juganson K, Ivask A, Kasemets K, Mortimer M, Kahru A (2013) Toxicity of Ag, CuO and $\mathrm{ZnO}$ nanoparticles to selected environmentally relevant test organisms and mammalian cells in vitro: a critical review. Arch Toxicol 87: 1181-1200. doi: 10.1007/s00204-013-1079-4 
8. Chu, W, Hu J, Bond T, Gao N, Xu B, Yin D (2016) Water temperature significantly impacts the formation of iodinated haloacetamides during persulfate oxidation. Water Res 98: 47-55. https://doi.org/10.1016/j.watres.2016.04.002

9. Dada AO, Adekola F, Adeyemi O, Bello O, Oluwaseun A, Awakan O Grace F (2018) Exploring the Effect of Operational Factors and Characterization Imperative to the Synthesis of Silver Nanoparticles, DOI: 10.5772/intechopen.76947.

10. Dubey SP, Lahtinen M, Sillanpa M (2010) Tansy fruit mediated greener synthesis of silver and gold nanoparticles. Process Biochem 45: 1065-1071. https://doi.org/10.1016/j.procbio.2010.03.024

11. Duran N, Marcato P, De Conti R, Alves O, Costa F, Brocchi M (2010) Potential use of silver nanoparticles on pathogenic bacteria, their toxicity and possible mechanisms of action. J Braz Chem Soc 21: 949-959.

12. Elechiguerra JL, Burt J, Morones J, Camacho B, Gao X, Lara H, Yocaman M (2005) Interaction of silver nanoparticles with HIV-1. J Nanobiotechnol. https://doi:10.1186/1477-3155-3-6. doi: 10.1186/1477-3155-3-6.

13. El-Shahawy A, EL Moaty S, El-Shatoury S, Nafady A (2020) Performance assessment of stabilization ponds receiving wastewater of high organic load and feasibility of treatment using actinobacteria. Desalin Water Treat 184:292-305. https://doi.org/10.5004/dwt.2020.25367

14. Erico RC, Noelia B, Tanya P, Gonzalo RS (2016) Green synthesis of silver nanoparticles by using leaf extracts from the endemic Buddleja globose hope. Green Chem Lett Rev 10: 250-256. https://doi.org/10.1080/17518253.2017.1360400

15. Fahim R, Lu X, Jilani G, Hussain J, Hussain I (2019) Comparison of floating-bed wetland and gravel filter amended with limestone and sawdust for sewage treatment. Environ Sci Pollut Res 26:2040020410. https://doi.org/10.1007/s11356-019-05325-5

16. Fayaz AM, Balaji K, Girilal M, Yadav R, Kalaichelvan P, Venketesan R (2010) Biogenic synthesis of silver nanoparticles and their synergistic effect with antibiotics: a study against gram-positive and gram-negative bacteria. Nanomed Nanotechnol Biol Med 6:103109. https://doi.org/10.1016/j.nano.2009.04.006

17. Ferroudj N, Nzimoto J, Davidson A, Talbot D, Briot E, Dupuis V, Abramson S (2013) Maghemite nanoparticles and maghemite/silica nanocomposite microspheres as magnetic Fenton catalysts for the removal of water pollutants. App Catal B: Environ 136, 9-

18. https://doi.org/10.1016/j.apcatb.2013.01.046

18. Gelagutashvili E (2013) Comparative Study on Heavy Metals Biosorption by Different Types of Bacteria. Open J Met 3: 62-67. DOI: 10.4236/ojmetal.2013.32A1008

19. Guzmán MG, Dille J, Godet S (2008) Synthesis of silver nanoparticles by chemical reduction method and their antibacterial activity. Int J Miner Metall Mater 2: 91-98. DOI: 10.7897/2230-8407.041024

20. Harajyoti M, Ahmed G (2011) Synthesis of silver nanoparticles and its adverse effect on seed germinations in Oryzasativa, vignaradiata and Brassica campestris. Int J Adv Biotechnol Res 2: 404413. 
21. Jannathul FM, Lalitha P (2015) Biosynthesis of Silver Nanoparticles and Its Applications. J of Nanotech 1-19. http://dx.doi.org/10.1155/2015/829526

22. Kumari J, Mamta B, Ajeet S (2016) Characterization of silver nanoparticles synthesized using Urticadioica Linn. leaves and their synergistic effects with antibiotics. J Radiat Res Appl Sci 9:217227. https://doi.org/10.1016/j.jrras.2015.10.002

23. Li H, Jiang D, Huang Z, He K, Zeng G, Chen A, Yuan L, Peng M, Huang T, Chen G, (2019) Preparation of silver-nanoparticle-loaded magnetic biochar/poly (dopamine) composite as catalyst for reduction of organic dyes. J Colloid Interface Sci 555: 460-469. https://doi.org/10.1016/j.jcis.2019.08.013

24. Li L, Hu Q, Zeng J, Qi H, Zhuang G (2011) Resistance and biosorption mechanism of silver ions by Bacillus cereus biomass. J Environ Sci 23(1): 108-111. https://doi.org/10.1016/S10010742(10)60380-4

25. Lufsyi M, Edi S, Agung B, Kamsul A (2015) Optical Properties of Silver Nanoparticles for Surface Plasmon Resonance (SPR)-Based Biosensor Applications. J Mod Phys 6: 1071-1076. http://dx.doi.org/10.4236/jmp.2015.68111

26. Mahmood SN, Naeem S, Basit N, Usmani T (1993) Microbial evaluation of silver coated/impregnated sand for purification of contaminated water. Environ Technol, 14, 151-157. https://doi.org/10.1080/09593339309385274

27. Marambio-Jones C, Hoek E (2010) A review of the antibacterial effects of silver nanomaterials and potential implications for human health and the environment. J Nanoparticle Res 12:1531-1551. DOI 10.1007/s11051-010-9900-y

28. Matsumura Y, Yoshikata K, Kunisaki S, Tsuchido T (2003) Mode of bactericidal action of silver zeolite and its comparison with that of silver nitrate. Appl Environ Microbiol 69: 4278-4281. doi: 10.1128/AEM.69.7.4278-4281.2003

29. Mpenyana-Monyatsi L, Mthombeni N, Onyango M and Momba M (2012) Cost-Effective Filter Materials Coated with Silver Nanoparticles for the Removal of Pathogenic Bacteria in Groundwater International. Int J Environ Res Public Health 9: 244-271. https://doi.org/10.3390/ijerph9010244

30. Mthombenia NH, Mpenyana-Monyatsi L, Onyango M, Momba M (2012) Breakthrough analysis for water disinfection using silver nanoparticles coated resin beads in fixed-bed column. $\mathrm{J}$ Hazard Mater 217- 218 133- 140. https://doi.org/10.1016/j.jhazmat.2012.03.004

31. Nangmenyi, G, Yue Z, Mehrabi S, Mintz E, Economy J (2009) Synthesis and characterization of Ag nanoparticle impregnated fiberglass and utility in water disinfection. Nanotech 20: 495-505. DOI: 10.1088/0957-4484/20/49/495705

32. Nath SS, Chakdar D, Gope G (2007) Synthesis of CdS and ZnS quantum dots and their applications in electronics. Nano Trends 2: 40-44.

33. Pasricha A, Jangra S, Singh N, Dilbaghi N, Sood K, Arora K, Pasricha R, (2012) Comparative study of leaching of silver nanoparticles from fabric and effective effluent treatment. J Environ Sci 24(5): 852-859. https://doi.org/10.1016/S1001-0742(11)60849-8 
34. Parisa G, Mozhgan S, Masoud H, Farideh N, Susan A, Rosfarizan M, Amin B (2015) Sumac Silver Novel Biodegradable Nano Composite for Bio-Medical Application: Antibacterial Activity. Molecules 20: 12946-12958. https:// doi:10.3390/molecules200712946

35. Phanjom P, Ahmed G (2015) Biosynthesis of Silver Nanoparticles by Aspergillus oryzae (MTCC No. 1846) and Its Characterizations. Nanosci Nanotechnol 5(1): 14-21. DOI: 10.5923/j.nn.20150501.03

36. Preetha D, Prachi K, Chirom A, Arun R (2013) Synthesis and characterization of silver nanoparticles using cannonball leaves and their cytotoxic activity against MCF-7 cell line. J Nanotechnol:1-5. https://doi.org/10.1155/2013/598328

37. Quang DV, Sarawade P, Hilonga A, Kim J, Chai Y, Kim S, Ryud J, Kim H (2011) Preparation of silver nanoparticle containing silica micro beads and investigation of their antibacterial activity. Appl Surf Sci 257: 6963-6970. https://doi.org/10.1016/j.apsusc.2011.03.041

38. Que ZG, Torres J, Vidal H, Rocha M, Pérez J, López I, Romero D, Reyna A, Sosa J, Pavón A, Hernández J (2018) Silver Nanoparticles - Fabrication, Characterization and Applications. In: Application of Silver Nanoparticles for Water Treatment. http://dx.doi.org/10.5772/intechopen.74675

39. Sathiya CK, Akilandeswari S (2014) Fabrication and characterization of silver nanoparticles using Delonix elata leaf broth. Acta Part A: Mol Biomol Spectrosc 128: 337-341. https:// doi.org/ 10.1016/j.saa.2014.02.172

40. Sathyavathi R, Krishna M, Rao S, Saritha R, Rao D (2010) Biosynthesis of silver nanoparticles using Coriandrum Sativum leaf extract and their application in nonlinear optics. Adv Sci Lett 3:16. doi:10.1166/asl.2010.1099

41. Sayed R, Saad H, Hagagy N (2018) Silver nanoparticles: characterization and antibacterial properties. Rend Fis Acc Lincei 29: 81-86. https://doi.org/10.1007/s12210-017-0663-6

42. Selvi BCG, Madhavan J, Santhanam A (2016) Cytotoxic effect of silver nanoparticles synthesized from Padina tetrastromatica on breast cancer cell line. Adv Nat Sci: Nanosci Nanotechnol 7: 1-8. https:// doi:10.1088/2043-6262/7/3/035015.

43. Standards and specifications for liquid wastes when discharged into the aquatic environment, Egypt, 2015.

44. Sun Y, Chen Z, Wu G, Wu Q, Zhang F, Niu Z, Hu H (2016) Characteristics of water quality of municipal wastewater treatment plants in China: implications for resources utilization and management. $J$ Clean Prod 131: 1-9. https://doi.org/10.1016/j.jclepro.2016.05.068

45. Tsibakhashvili NY, Kirkesali E, Pataraya D, Gurielidze M, Kalabegishvili T, Gvarjaladze D, Tsertsvadze G, Frontasyeva M, Zinicovscaia I, Wakstein M, Khakhanov S, Shvindina N, Shklover V (2011) Microbial Synthesis of Silver Nanoparticles by Streptomyces glaucus and Spirulina platensis. Adv Sci Lett 4: 1-10. DOI: 10.1166/asl.2011.1915

46. Vasudeva RN, Suman B, Latha D, Soneya S, Sindhu G, Murali S, Venkata S, Saritha K, Vijaya T (2018) Biogenesis of silver nanoparticles using leaf extract of Indigofera hirsuta L. and their potential biomedical applications (3-in-1 system). Artif Cells Nanomed Biotechnol 1-11. https://doi.org/ $10.1080 / 21691401.2018 .1446967$ 
47. Vidhyashree N, Yamini D, Lakshmi S (2015) Screening, Isolation, Identification, Characterisation and Applications of Silver Nanoparticles Synthesized from Marine Actinomycetes (Streptomyces grieseorubens). World J Pharm Res 4 (08): 1801-1820.

48. Wagi S, Ahmed A (2020) Bacterial nanobiotic potential, Green Process Synth, 9: 203-211. DOI: 10.1515/gps-2020-0021

49. Wang W, Huang G, Jimmy C, Wong P (2015) Advances in photocatalytic disinfection of bacteria: development of photocatalysts and mechanisms. J Environ Sci 34: 232247. https://doi.org/10.1016/j.jes.2015.05.003

50. WHO (World Health Organization) (2015) Drinking-water: Fact sheet No. 391. http://www.who.int/mediacentre/factsheets/fs391/en

\section{Figures}

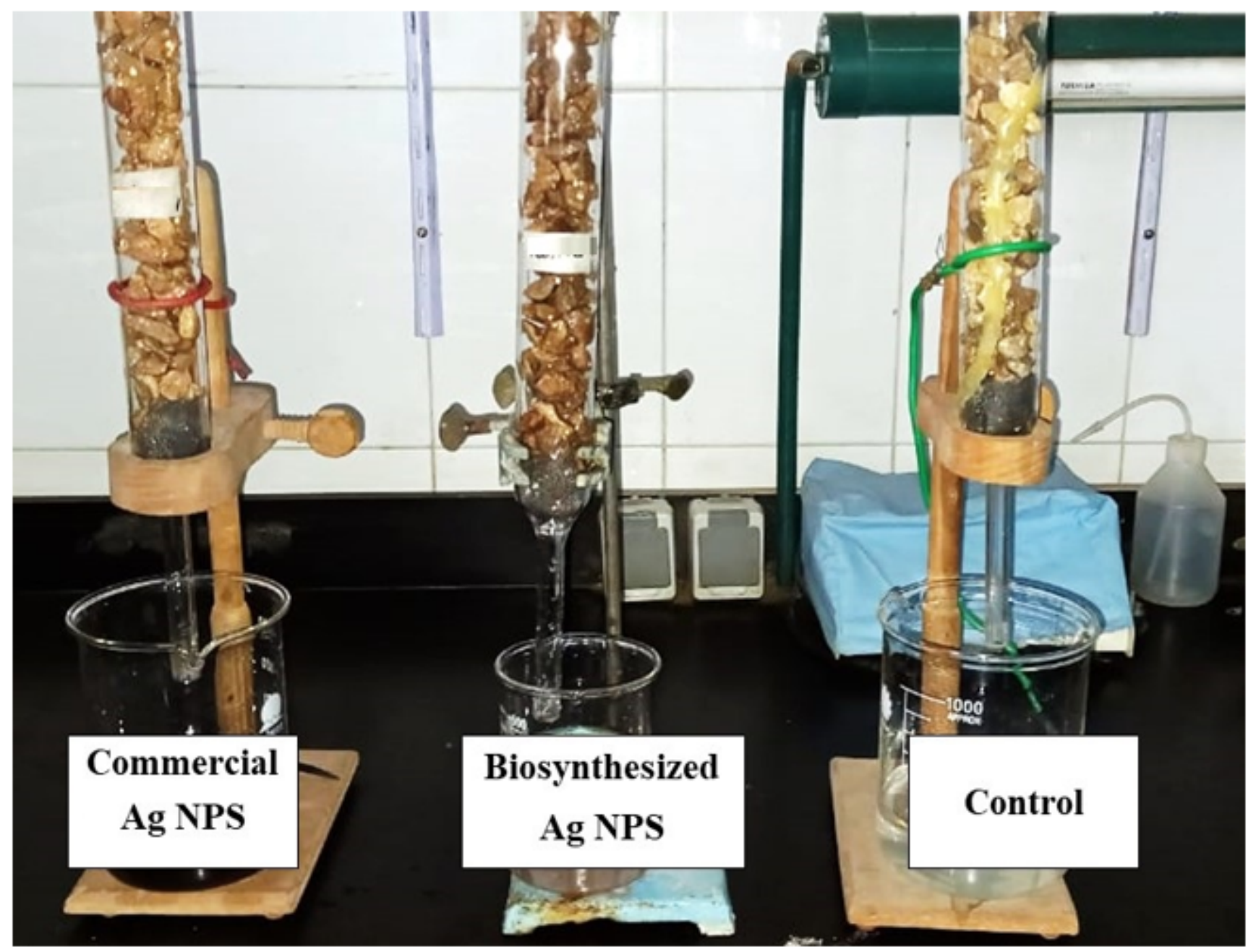

\section{Figure 1}

Gravel columns loaded with biosynthesized and commercially ink Ag NPs in compared to control. 

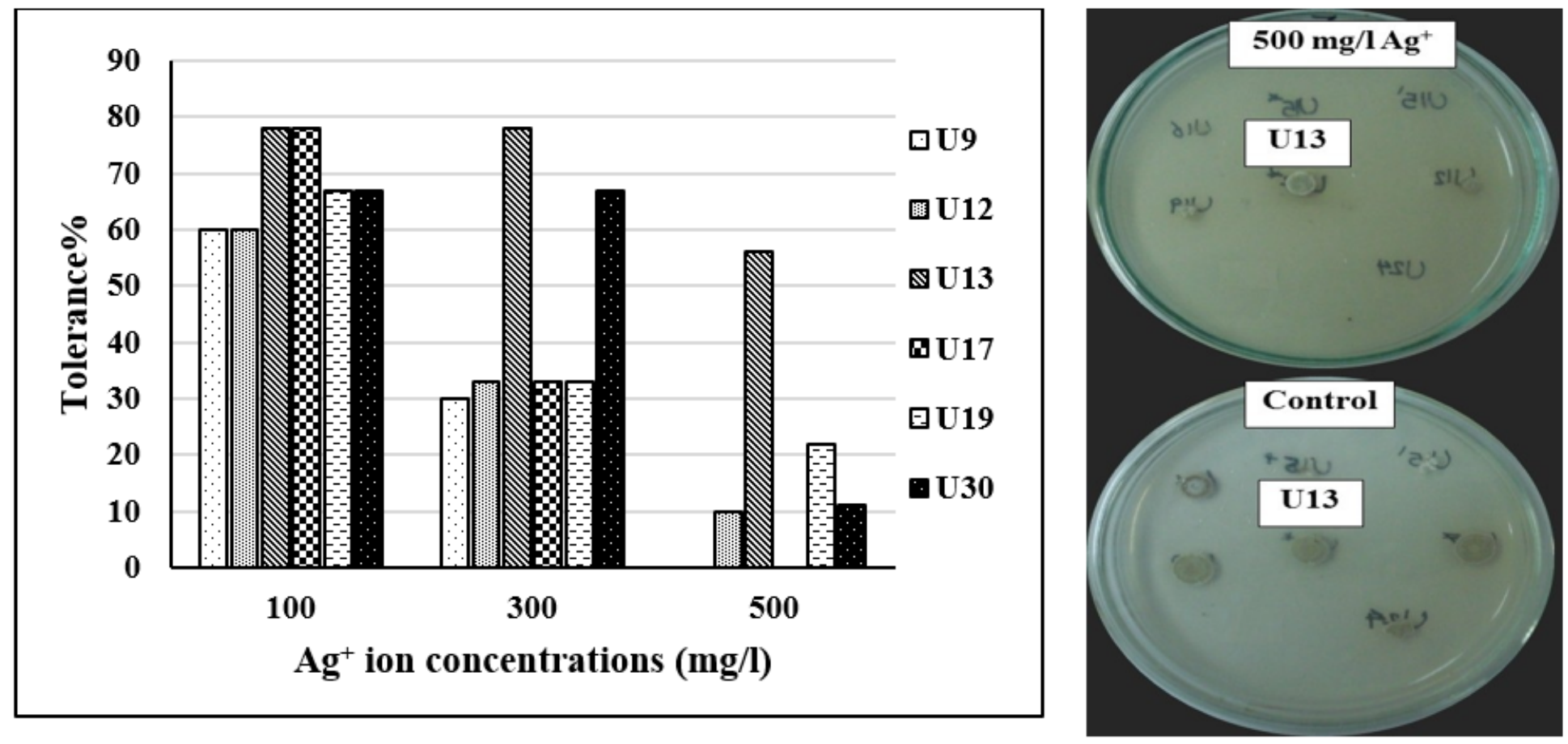

Figure 2

Tolerance percentage of selected actinomycete strains to different concentrations of Ag+.

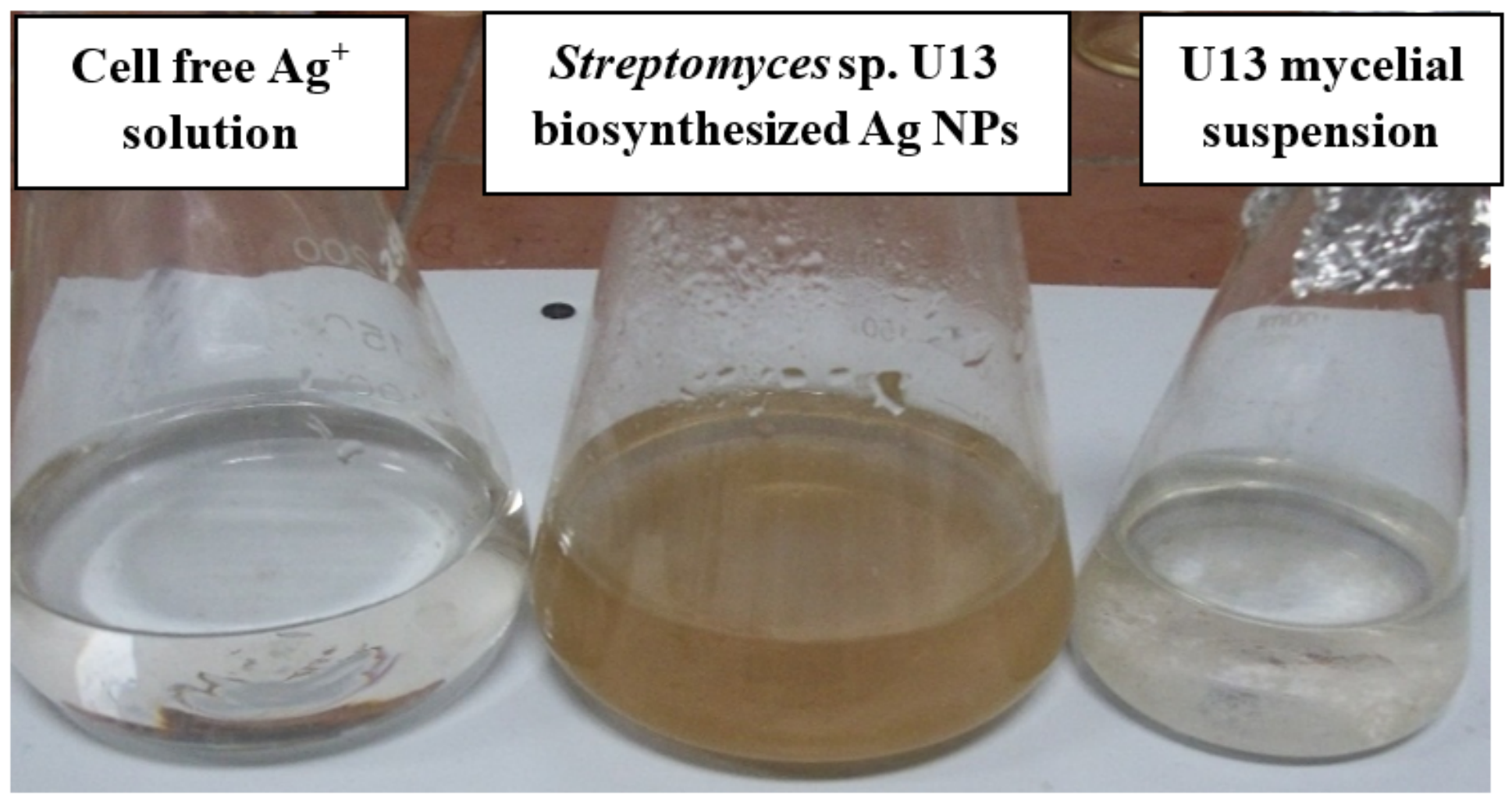

Figure 3

Biosynthesis of Ag NPs by Streptomyces sp. U13 actinomycete strain showing change of color to brown. 


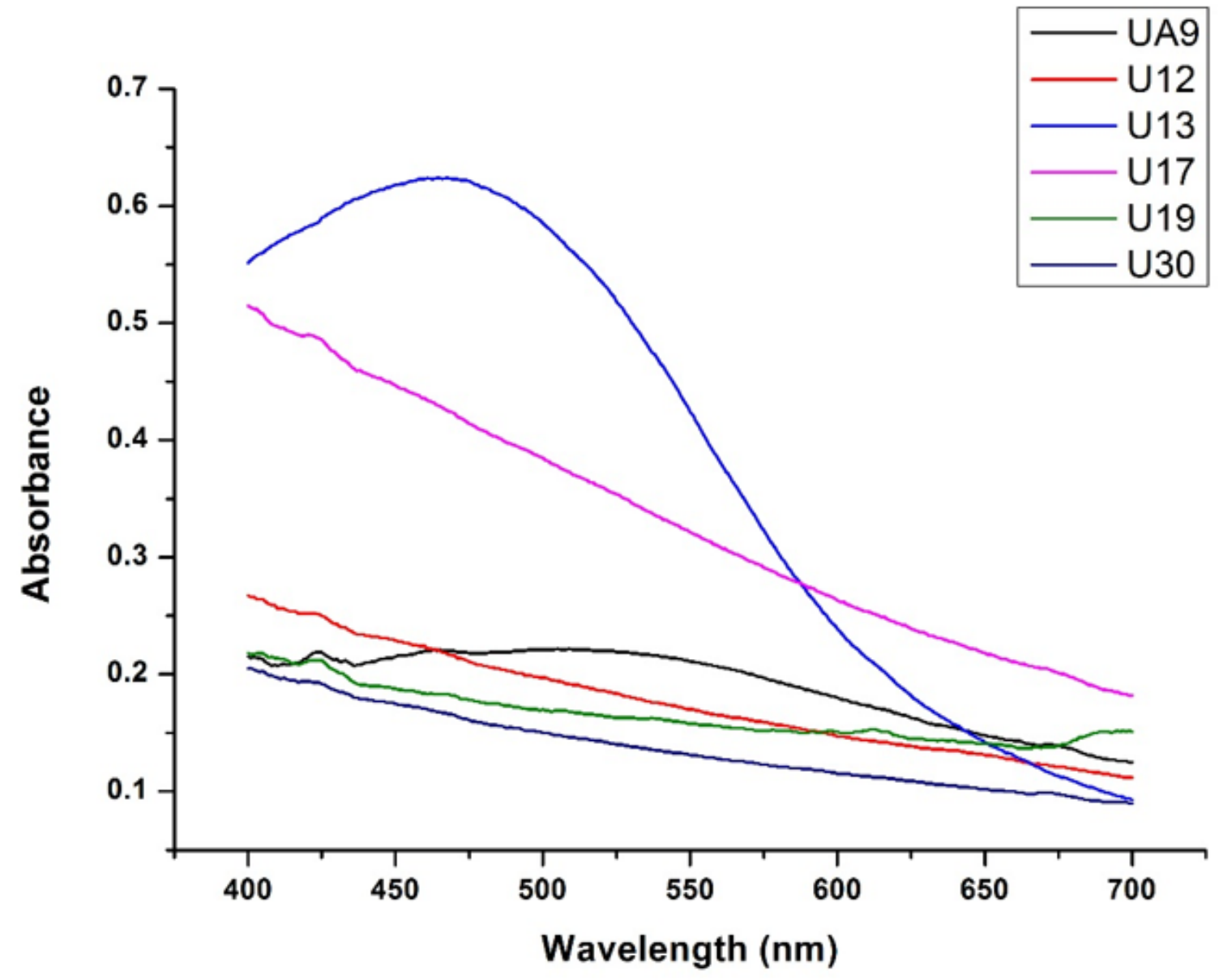

Figure 4

UV-Vis scan of extracellular Ag NPs formed by the six tested actinomycete strains. 


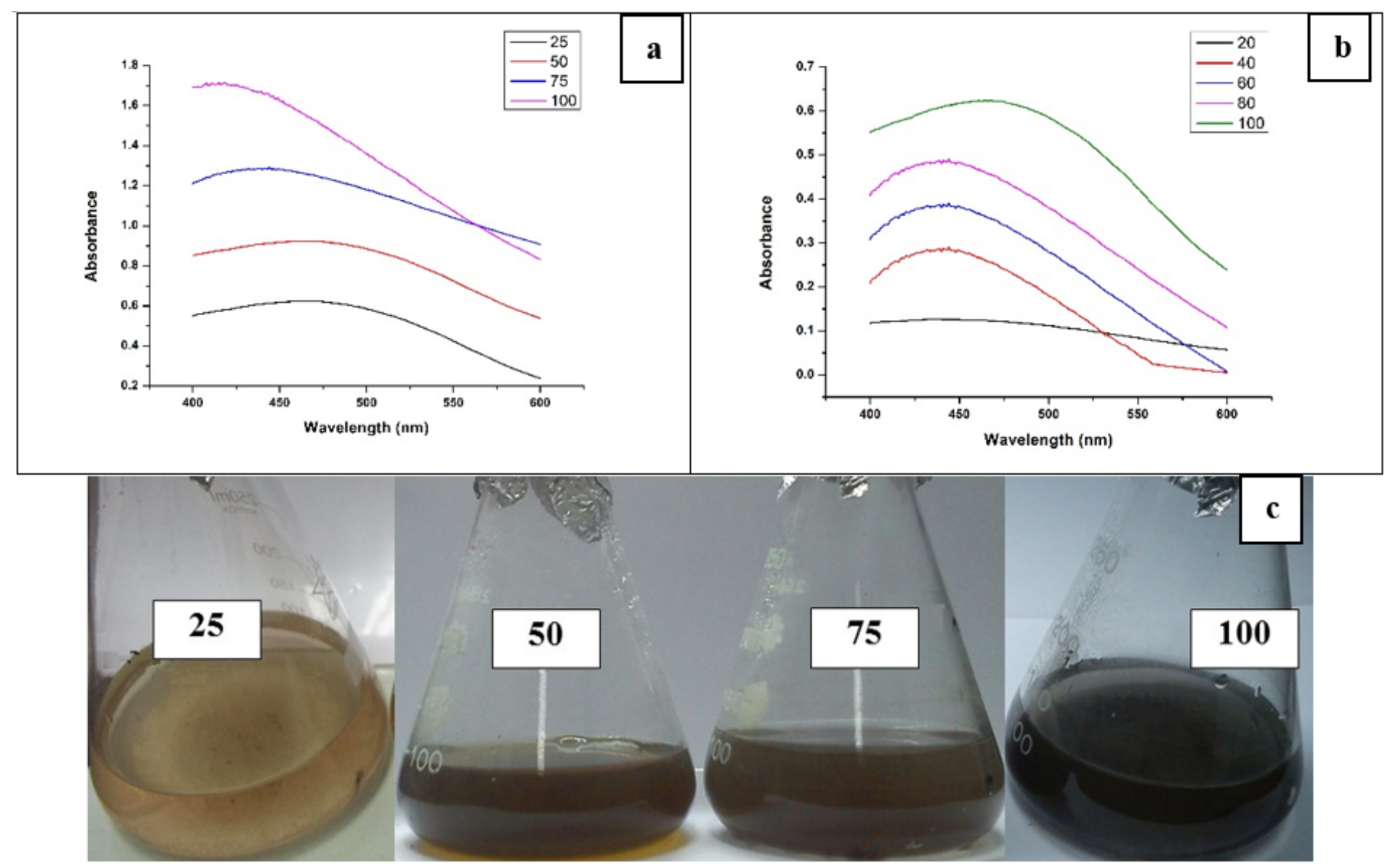

Figure 5

Biosynthesis of Ag NPs by Streptomyces sp. U13. UV-Vis spectra at different Ag+ concentration $(25,50$, 75 and $100 \mathrm{mg}$ ) (a) UV-Vis spectra at different biomass weights $(20,40,60,80$ and $100 \mathrm{mg}$ dry weight equivalent) (b) and image of color change during biosynthesis process at different Ag+ concentration (c). 

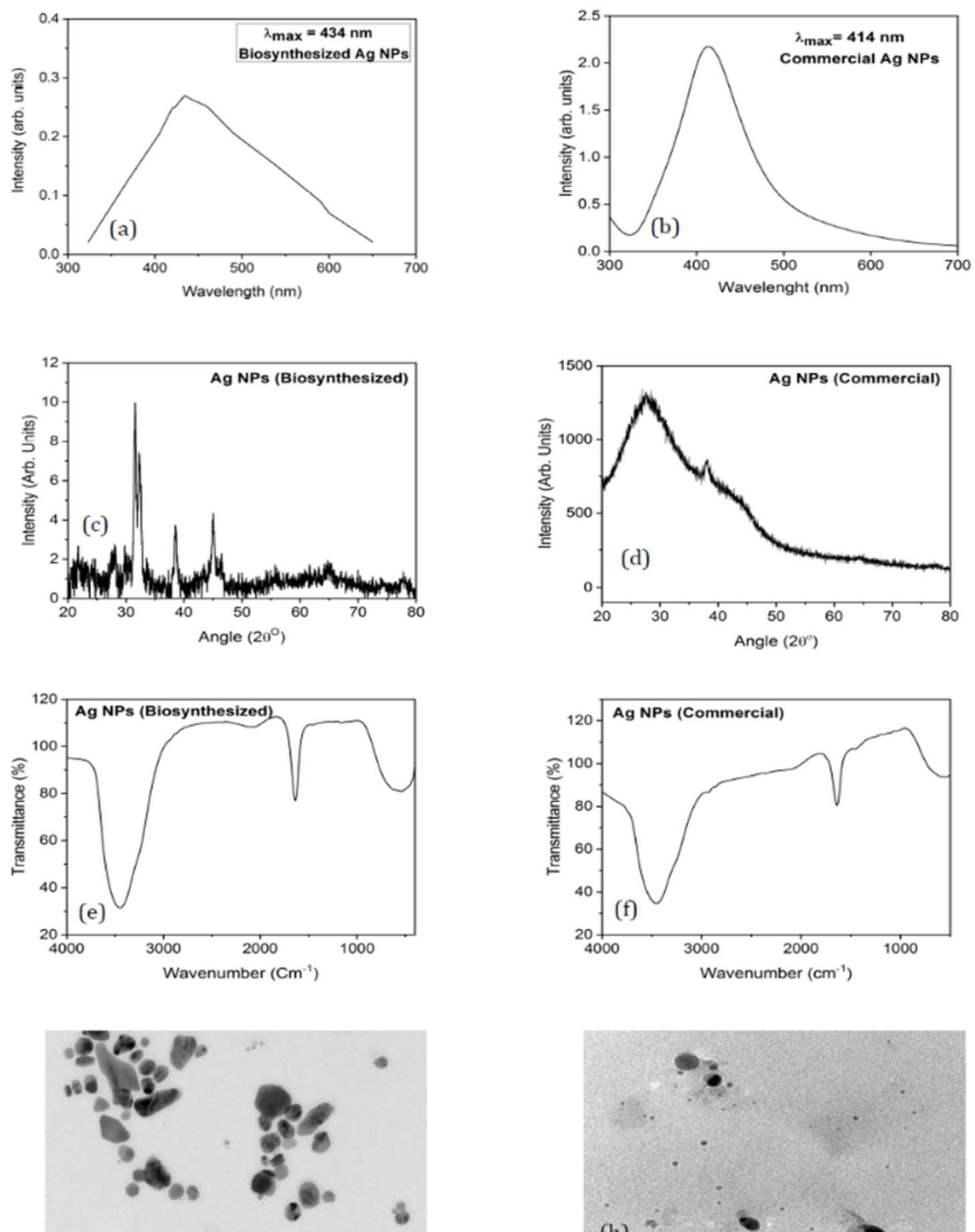

(g)

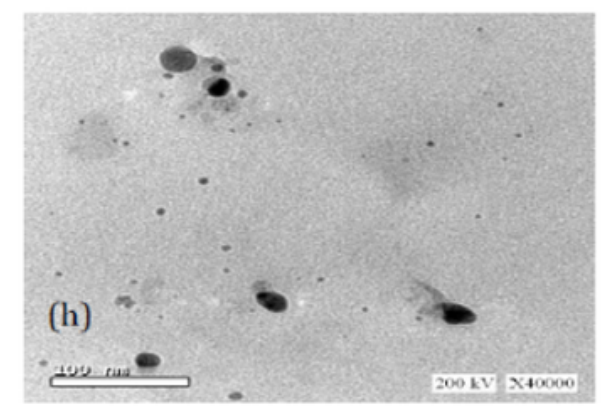

\section{Figure 6}

Characteristics of silver nanoparticles. UV-Vis spectra of biosynthesized Ag NPs (a), UV-Vis spectra of commercially available Ag NPs (Ink Ag NPs) (b), XRD patterns of biosynthesized Ag NPs (c), XRD spectra of ink Ag NPs (d), FTIR spectra of biosynthesized Ag NPs (e), FTIR spectra of ink Ag NPs (f), TEM image of biosynthesized Ag NPs (g) and TEM image of ink Ag NPs (h). 

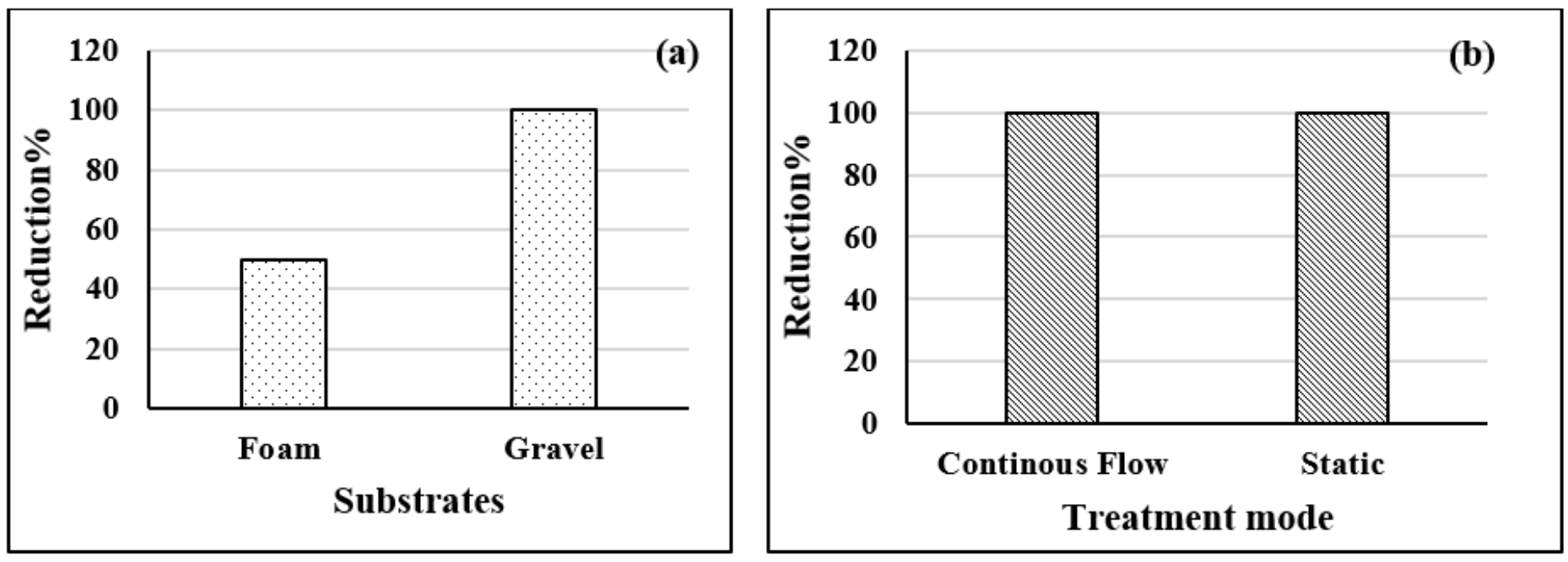

Figure 7

Reduction percentage of total coliform of wastewater using two different substrates in column experiment (a) Reduction percentage of total coliform of wastewater using two different disinfection modes of limestone gravel column after 6 hrs (b).

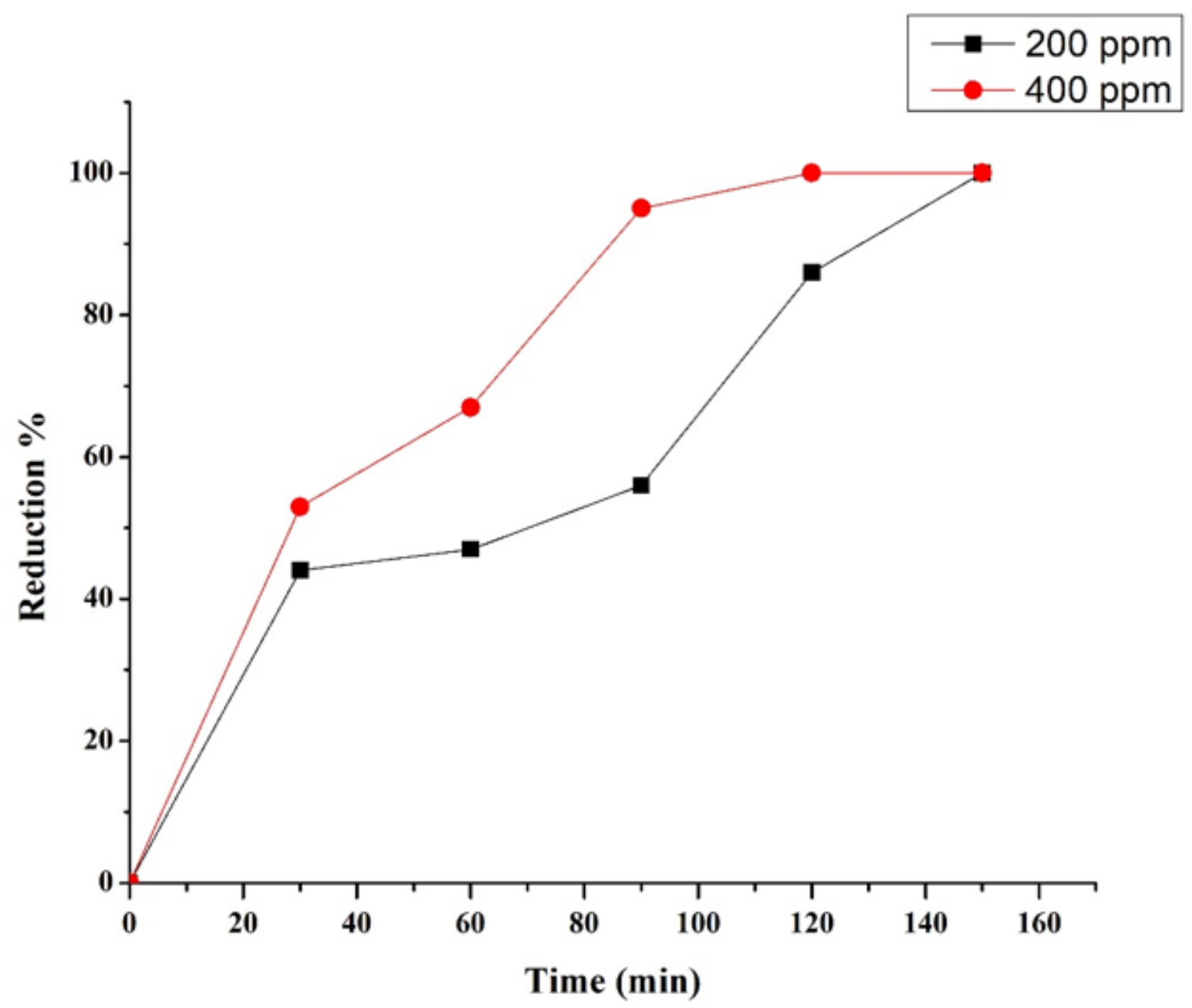


Figure 8

Time course of the disinfection process using two different concentrations of biosynthesized Ag NPs, 200 and 400 ppm.

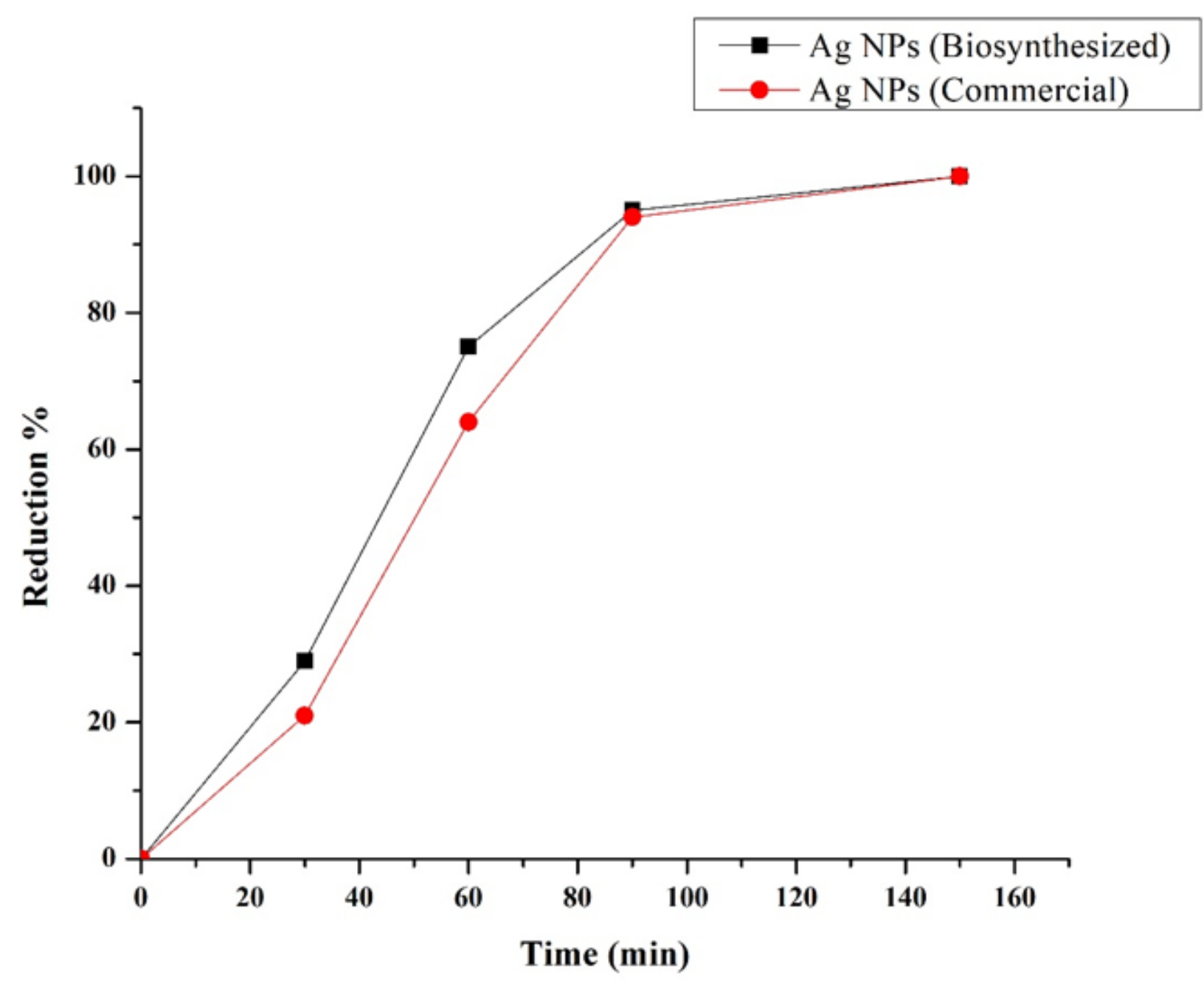

Figure 9

The efficiency of the biosynthesized Ag NPs compared to commercial Ag NPs (Ink nanosilver) in disinfection process (the loaded concentration of each was $200 \mathrm{mg} / \mathrm{l}$ ). 